\title{
Potential implications of differential preservation of testate amoebae shells for paleoenvironmental reconstruction in peatlands
}

Edward A.D. Mitchell ${ }^{1,2}$, Richard J. Payne ${ }^{3}$, Mariusz Lamentowicz ${ }^{4}$

${ }^{1}$ WSL Swiss Federal Research Institute, Ecosystem Boundaries Research Unit, Wetlands Research Group, Station 2, CH-1015 Lausanne, Switzerland. E-mail: edward.mitchell@wsl.ch

${ }^{2}$ Ecole Polytechnique Fédérale de Lausanne, Laboratory of Ecological Systems, Station 2, CH-1015 Lausanne, Switzerland

${ }^{3}$ Geography, School of Environment and Development, The University of Manchester, Oxford Road, Manchester, M13 9PL, United Kingdom.

${ }^{4}$ Department of Biogeography and Palaeoecology, Adam Mickiewicz University, Dzięgielowa 27, 61-680 Poznań, Poland.

Keywords: testate amoebae; taphonomy; water table depth; moisture; paleoecology; paleoclimate; peat; bog; fen; Sphagnum; transfer function;

Running title: testate amoebae taphonomy and paleoecology 


\section{Abstract}

Testate amoebae are now commonly used in paleoenvironmental studies but little is known of their taphonomy. There is some experimental evidence for differential preservation of some testate amoeba shell types over others, but it is unclear what, if any impact this has on palaeoenvironmental reconstruction. To investigate this issue we looked at palaeoecological evidence for the preservation of different shell types and then applied this to investigate the possible impact of selective preservation on quantitative palaeoenvironmental inference. We initially used previously derived palaeoecological data sets to assess the vertical patterns of relative abundance in four testate amoeba shell types. In three testate amoeba diagrams a clear pattern of decay was only observed for the idiosome shell type with a rapid loss of tests in the upper portions of the sequences, the three other types did not show any consistent pattern. In order to assess the implications of differential preservation of testate amoeba taxa for paleoenvironmental reconstruction we then carried out simulations using three existing transfer functions and a wide range of scenarios, downweighting different test categories to represent the impact of selective test decomposition. Simulation results showed that downweighting generally reduced overall model performance. However downweighting a shell type only produced a consistent directional bias in inferred water table depth where a given shell type is both dominant and shows a clear preference along the ecological gradient. Of the data-sets tested here the greatest cause for concern is in data from minerotrophic peatlands in Greece where loss of idiosome tests (the most probable result of selective decomposition) leads to consistent underestimation of water table depth. The extent to which differential preservation leads to reconstruction bias in real palaeoecological data will depend on the extent of shell decomposition. In Sphagnum-dominated ombrotrophic mires the 
proportion of idiosome tests is usually lower and the impact of their loss is likely to be limited. Applying a scenario derived from previous experimental work did not lead to any significant difference in inferred water table depth. 


\section{Introduction}

One of the basic assumptions that need to be fulfilled if a group of organisms is to be used in paleoecology is that the taphonomy should be well understood (Birks and Birks 1980). Ideally there should not be any differential preservation of some taxa over others during the slow decay that inevitably affects the record. However, differential preservation is a reality of Quaternary palaeoecology and in the absence of perfect preservation it is essential to understand the causes and impacts of these processes. For this reason the taphonomy of many groups of organisms used in paleoecology has been studied (Barker 1992; Campbell 1999; Kontrovitz et al. 1998). One notable exception is the group of testate amoebae that are increasingly used in paleoenvironmental studies. Testate amoebae have been particularly used in palaeoecological studies from peatlands where the hydrological preferences of amoebae species have allowed the use of transfer functions to quantitatively reconstruct past changes in mire wetness, and thereby climate. Testate amoebae have only recently become part of the standard toolkit of paleoecologists and their taphonomy has not been well studied.

The existence of vertical micro-distribution of testate amoebae in the upper part of Sphagnum peatlands in response to micro-environmental gradients has long been established (Bonnet 1958; Booth 2002; Chacharonis 1954, 1956; Meisterfeld 1977; Mitchell and Gilbert 2004). With respect to the subfossil communities, Tolonen observed that the siliceous plates (referred to as "idiosomes") characteristic of, for instance, Euglypha species are very soluble in peat (Tolonen 1986). Ruzicka (1982) estimated the depth at which $10 \%$ of the initial number of testate amoebae tests remained in lake deposits. The estimated depth varied considerably between taxa that 
produce proteinaceous tests (e.g. Hyalosphenia elegans: $809 \mathrm{~cm}$ ) and those that build their test from recycled organic and/or mineral particles (referred to as "xenosomes", e.g. Centropyxis: $335 \mathrm{~cm}$, Difflugia: $232 \mathrm{~cm}$, Heleopera: $352 \mathrm{~cm}$, Euglypha: $353 \mathrm{~cm}$ ). More recently, Roe et al. (2002) observed a progressive decline in the abundance of testate amoebae shells in the top $18 \mathrm{~cm}$ of saltmarsh sediments and that test made of idiosomes were less well preserved than those made of xenosomes. Wilmhurst et al. (2003) observed clear differences between modern and subfossil communities in peatlands. Wilmhurst et al. (2003) showed that there was good overlap between the position of exclusively modern species and those also present in the fossil record and therefore the observed difference is not due to major ecological shifts but rather to differential preservation. However no attempt has been made to quantitatively assess if there is a systematic bias in shell type with depth within the catotelm peat.

Studies of the decomposition of testate amoeba shells in upland forest litter were carried out by Lousier and Parkinson (1981) and Coûteaux (1992). Lousier and Parkinson (1981) observed high decomposition (74-97\% after one week) of shells build from platelets (idiosomes) and lower decomposition (42-68\% after one week) for species that build shells from rediment particles (xenosomes). However, Coûteaux (1992) did not observe any significant decay in the course of a five-week long experiment. In a recent study, Swindles and Roe (2007) experimentally tested how different testate amoebae extracted from Sphagnum resisted extreme acidic conditions ( $\mathrm{pH} 0.3-0.5)$. These conditions, which are about three $\mathrm{pH}$ units below the lowest valued typically observed in ombrotrophic bogs, allowed the authors to observe significant shell decay over a period of only four days. Swindles and Roe observed a relatively wide degree of variability in resistance to decay, even within given genera 
(e.g. Assulina, Nebela) and concluded that this could represent a problem for peatbased palaeoclimate studies. Payne (in press) subjected peat samples to a variety of treatments over a 28-month period. Significant changes were noted in dried samples and samples treated with strong acids, but the possibility of prior differences in the samples cannot be excluded. Recognising the problem of differential preservation Booth and Jackson (2003) and Booth et al (2004) excluded taxa not present below the accrotelm from their training set for palaeoenvironmental reconstruction. To date no assessment has been made of the implications of possible differential preservation of testate amoebae tests for paleoenvironmental reconstruction.

The first way to assess if there is indeed a trend for some shell types to be preferentially lost over time is to compare the relative contribution of different shell types to the total community from the surface downwards. However, as pointed out by Swindles and Roe (2007), such a comparison is not necessarily pertinent because the vertical patterns of testate amoeba communities may be due to their response to changes in environmental conditions as well as to differential preservation of shells. An alternative option is to compare the relative percentage of different shell categories in subfossil samples with modern samples from a range of microhabitats. The possible bias here is that the present and past range of microhabitats may be significantly different (e.g. if a broader range of habitats were sampled for the training set and the subfossil sequence only covers part of the ecological gradient).

Despite the wide range of testate amoeba shell types that are expected to differ in their resistance to decay, differential preservation of shells would only matter if the 
ecological preferences of the different categories of shells were significantly different and this has not been assessed to this date with the exception of the above-mentioned study of Wilmhurst et al. (2003). Our goals were therefore 1) to assess if the contribution of different shell types varies with depth using several published and unpublished paleoecological data sets (Lamentowicz 2005; Lamentowicz et al. 2007; Lamentowicz et al. In prep; Lamentowicz et al. In Press; Mitchell et al. 2001), 2) to assess if the ecological preferences of testate amoebae characterized by various categories of shells were significantly different, using data sets currently used for transfer functions (Lamentowicz and Mitchell 2005; Mitchell et al. 1999; Mitchell et al. 2001; Payne and Mitchell 2007; Payne et al. 2006). Using these same data sets we then conducted a theoretical experiment in which we selectively filtered out various proportions of different shell types and assessed how this affected the performance of the models and what bias this cause in the inferred water table depth.

\section{Methods}

Data sets

To assess if a pattern of differential preservation existed among the various test types of testate amoebae three data sets were used, from Alaska (Jigsaw Lake, Kenai Peninsula, E. Mitchell and K. Kishaba, unpublished data), the Jura Mountains of Switzerland (Praz-Rodet bog) (Mitchell et al. 2001), and Poland (Tuchola mire) (Lamentowicz 2005; Lamentowicz et al. In prep).

To assess if testate amoebae with different test types also had different 
ecological preferences, three data sets were used: one from Alaska (Payne et al. 2006), one from the Jura Mountains of Switzerland and France (Mitchell et al. 1999), and one from northern Greece (Payne and Mitchell 2007). The final (selected) data was used with the best performing transfer function model; this was a two-component weighted average partial least squares (WA-PLS) model for the Alaskan data and a maximum likelihood (ML) model for the Greek data. For the Jura data the original study only tested simple weighted averaging, re-analysis here showed this to be out-

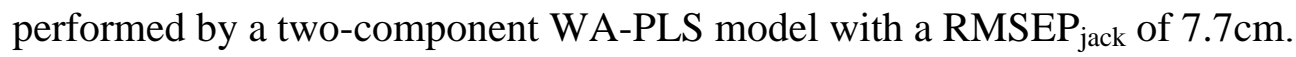

Categories of test types and modelling simulations

We divided testate amoebae taxa into four categories on the basis of test construction. The four categories used were:

1) Idiosomes. This category includes all testate amoebae which produce biosilica or calcite plates but which do not embed the plates in a thick organic matrix. Examples include: Corythion, Euglypha, Quadrulella, Sphenoderia, Tracheleuglypha and Trinema. Most of these taxa belong to the Euglyphida (testate amoebae with filose pseudopodia).

2) Idiosomes + organic. This category includes all testate amoebae which produce biosilica or calcite plates and which do embed the plates in a thick organic matrix. One genus is included: Assulina. This genus also belongs to the Euglyphida. This genus is well known to palynologists because it is one of the few testate amoebae to resist the acid digestion used in pollen preparations. It is clear from palaeoecological studies that tests of this category are more resistant to decomposition than tests constructed of idiosomes without an organic matrix, so it is important that 
these groups are separated here.

3) Protein + calcium. This category includes all taxa that secrete their test but do not build biosilica or calcite. Examples include: Arcella, Archerella (syn. Amphitrema flavum, the other Amphitrema species are in the xenosome categories), and Hylosphenia.

4) Xenosomes. This category includes the taxa that recycle organic or mineral particles from their environment or from their prey and glue these particles together with an organic cement. Examples include: Amphitrema, Centropyxis, Cyclopyxis, Difflugia, Heleopera, Nebela, Phryganella, Pseudodifflugia. Taxa from the last two categories belong to the Arcellinida, except for the genera Archerella and Amphitrema whose position in the tree of life is not established.

These groups were initially used to investigate down-core changes in test types in three palaeoecological data-sets. Subsequently the groups were used to investigate how the ecological preferences of testate amoebae taxa vary by test type. Finally, the groups were used in a series of experiments to investigate how selective preservation may affect quantitative inference of mire hydrology. As a first experimental stage each of the four groups was separately down-weighted from 1 (no change) to 0 (100\% loss of that type) by increments of 0.1 giving 40 scenarios. As a second experimental stage the groups were filtered simultaneously to give more realistic test decomposition scenarios. Idiosome tests were weighted from 0 to 0.4 , idiosome+organic tests from 0.4 to 0.9 , protein/calcium tests from 0.4 to 0.9 and xenosome tests from 0.1 to 0.6 giving 81 experimental scenarios (Table 1). Percentages were recalculated after each stage of filtering and the transfer function 
model applied to the filtered data-set. Bias from the measured DWT values were calculated.

Swindles \& Roe (2007) present the results of an experiment applying strong acids to tests. Results demonstrated significant change in some taxa concentrations which the authors suggest can be treated as a preliminary index of test robustness. To test the impact of these changes on inferred DWT values, these weightings were applied to each of the data-sets. Taxa not included in the results of Swindles \& Roe (in press) were left unchanged.

\section{Results}

Patterns of shell type preservation in paleoecological records

The three paleoecological data sets show similarities in that the testate amoebae belonging to the idiosome type rarely or never dominate the community and their contribution to the community seems to decline very fast with depth (Figure 1). For example in Jigsaw Lake the idiosome type represents $39 \%$ of the community in the uppermost sample but then only exceeds $5 \%$ in one sample of the paleoecological record. In Tuchola peatland (Poland) the pattern is similar with $7.7 \%$ in the top sample and less than $1 \%$ in the paleo samples. In Praz-Rodet, the drop is slower with $35-50 \%$ in the top $5 \mathrm{~cm}$, then dropping to below $10 \%$ below $15 \mathrm{~cm}$ depth and remaining below 3\% thereafter. No such pattern appears clearly for the other three types. 
Ecological preferences of testate amoebae differing in test type

In the Jura surface data set (Figure 2), testate amoebae with idiosome-type shells do not show a very clear preference along the water table gradient. They appear to have a bimodal response with peaks at 20 (the highest one) and $40 \mathrm{~cm}$ DWT and lower relative abundance at both extremes of the DWT gradient. Testate amoebae with idiosomes + organic type shells (Assulina) peak between 30 and $40 \mathrm{~cm}$ DWT, those with protein-type shells are most abundant at the wet end of the gradient (peat around $10 \mathrm{~cm}$ DWT), and those with xenosomes-type shells are slightly most abundant in the drier $2 / 3$ of the gradient. In the Alaska data set the patterns are quite similar to the Jura except that the protein-type reach a maximum between 20 and $40 \mathrm{~cm}$ rather than at the wettest end of the gradient. The Greece data set is clearly different from the Jura and Alaska data. Two shell-types strongly dominate the community: the idiosome type and the xenosome type (Figure 4). The idiosome type shows a clear preference for drier conditions while the xeonosome type is dominant in the wettest end of the gradient.

Model simulations: 1) selective loss of one shell-type

In the Jura data set (Figure 2), the effect of selective loss of each type on model prediction was mainly apparent for the most extreme cases (100\% loss of the type) and for the part of the gradient where the type being down-weighted was most abundant: In a few cases the DWT was overestimated when idiosome-type shells 
were lost and this effect was clearest for the samples in which this type was most abundant, at a DWT of ca. $20 \mathrm{~cm}$. The opposite effect is observed for the idiosome + organic type with a under-estimation of DWT for observed DWT between 30 and $40 \mathrm{~cm}$. For the protein type DWT is clearly overestimated at the wet end of the gradient when this shell type is lost and the opposite is observed for the xenosome type. In the Alaska data set (Figure 3), the effect of selective loss of each shell type mirrors that observed for the Jura data set. In the Greece data set (Figure 4), the effect of selective loss of idiosome types is a clear underestimation of the DWT in the dry end of the gradient. By contrast the selective loss of the xenosome type does not lead to an as-systematic bias in the predicted DWT: When a bias exists it is always towards higher DWT values (drier conditions) and at the dry end of the gradient the model surprisingly performs better (i.e. closer to the 1:1 line of observed vs. predicted DWT) when the xenosome type is lost.

In terms of overall model performance assessed by average bias from measured DWT (figure 5) downweighting shell types generally leads to a reduction in transfer function performance. The principal exception to this is for the xenosome shell type in the Greek data where moderate filtering actually improves model performance, suggesting that taxa with this shell type may be poor hydrological indicators. There is a general relationship between the impact of downweighting and the abundance of a shell type, so for instance xenosomes contribute the largest proportion of shells in the Jura data and their removal leads to the greatest reduction in model performance.

Model simulations: 2) scenarios of combined shell loss in the four types 
Figure 6 summarises the performance of the transfer functions under 81 different scenarios of differential preservation of the four testate amoeba shell-types. In the Alaska and Jura data sets all 81 cases perform similar to or worse than the full data set.

In the Jura data set the highest bias (measured as the average bias from measured DWT) is observed for the combination of highest loss of idiosomes and xenosomes shell-types. Overall however the xenosome type affects the performance of the model performance most. In the Alaska data set the pattern is clearer: the loss of the xenosome and idiosome shell-types strongly affects the performance of the model while the protein and idiosome + organic shell-types have little effect.

Model simulations: 3) Simulation according to the observations of Swindles \& Roe

Using the shell degradation values observed by Swindles and Roe (2007), no significant effect was observed in the predicted DWT (Figure 7). The changes in relative percentage contribution to the community of individual taxa $(+/-5 \%$ at most $)$ were however much lower than in our simulations.

\section{Discussion}

Patterns of shell type preservation in paleoecological records and implications for model building 
The paleo-record clearly suggests that differential preservation exists for the testate amoebae that build their shells from secreted biosilica plates (idiosomes). This category corresponds to the Euglyphid testate amoebae (genera Euglypha, Trinema, Corythion, Placocista, Tracheleuglypha, etc.). This observation, which is in agreement with previous ones in peatlands, lakes and saltmarshes (Roe et al. 2002; Ruzicka 1982; Tolonen 1986), leads us to question the inclusion of these taxa in the transfer functions. If they are lost so rapidly their inclusion in modern training sets and transfer function models will add little to palaeoecological inference. Worse, as these taxa can in some cases represent a relatively large proportion of the community, including them will mean that the total count of testate amoebae which are preserved will often be significantly lower than that usually assumed to be sufficient to characterise the community (e.g. in most cases 150 individuals). In our data sets the proportion of this category frequently exceeds $30 \%$ of the community in the Sphagnum-dominated peatlands and is $67 \%$ of the total in the Greece data set. Model simulations of $100 \%$ loss of the idiosome shell-type in the Greece data (Figure 4) set suggest that paleohydrological inference from testate amoebae in these peatlands may underestimate DWT. However, for Sphagnum-dominated peatlands the preferential loss of idiosome shell-types will not have a significant impact on the inferred DWT.

Ecological preferences of testate amoebae differing in test type and model simulations

The general patterns of ecological optima for the four different shell types are similar for the Jura and Alaska data sets but different for the Greece data set. This can be 
explained by difference in the types of peatlands studied: Sphagnum-dominated peatlands in the first two cases and Cyperaceous-dominated peatlands in Greece. Cyperaceous-dominated peatlands have been much less intensively studied for testate amoeba ecology than Sphagnum-dominated mires (Opravilova and Hajek 2006).

Implications for the use of testate amoebae in paleoecological studies and suggestions for future studies

According to Swindles and Roe (2007) the differential preservation of testate amoebae represents a particular problem for peat-based palaeoclimate studies. Our results suggest that, at least for Sphagnum-dominated peatlands, overall testate amoebae transfer functions are quite robust to even relatively large changes in community structure resulting from differential preservation of different shell types. The scale of change required to produce a significant bias from the full data is considerably greater than that shown experimentally by Swindles and Roe (2007). This is good news for the increasing number of people using testate amoebae as palaeoenvironmental indicators.

For more minerotrophic peatlands such as the sites of our Greece data set the situation may not be as favourable as the most sensitive idiosome tests constitute a larger proportion of the community and their loss may lead to a considerable bias in inferred water table. However existing studies from fens are few in number and it is not certain that idiosome tests always constitute such a high proportion of total tests in 
such sites, or that differential decomposition is as serious a concern in a less acidic peat environment. It is therefore too early to consider testate amoebae as a lost cause as a paleoecological tool in minerotrophic sedge-dominated peatlands.

A limitation of our study is that we might have lumped in a same category some testate amoeba taxa that differ significantly in their resistance to decay. For example Swindles and Roe (2007) showed that within given genera (e.g. Nebela, Assulina) resistance to extreme low $\mathrm{pH}$ condition could be different. As such our simulation experiments might give an over-simplified view of the impact of selective preservation on hydrological inferences. The existing data on testate amoeba shell decomposition is confusing. For example Lousier and Parkinson (1981) observed high decomposition rates while Coûteaux (1992) did not. An important difference between these two studies is that Lousier and Parkinson (1981) sterilized their samples by heating them to $80^{\circ} \mathrm{C}$ while Coûteaux used gamma rays and chemical sterilisation. The heat treatment might have weakened the organic cement that keeps the shells in shape and this would have caused a higher than natural decomposition rate. The experimental conditions used by Swindles and Roe $(2007)(\mathrm{pH}<1)$ are also extreme and their results by therefore not correspond to the true pattern of shell decomposition in nature. More decomposition experiments under more realistic conditions and including more taxa could be useful to complete our simulations with improved estimates of the preservation bias in testate amoeba shells.

Future work should aim to 1) clarify the ecology of testate amoebae across the full bog-fen gradient, 2) assess the possible different responses of taxa to ecological 
gradients across climatic gradients (e.g. oceanic-continental), 3) improve taxonomy and then address the possible existence of local (possible cryptic) taxa with different ecological optima - this is related to the ongoing debate about biogeography of freeliving microorganisms (Mitchell and Meisterfeld 2005)), 4) experimentally assess the resistance to decomposition of at least the main testate amoeba taxa used in transfer function and especially those with narrow tolerance to relevant environmental variables (the best indicators).

\section{Acknowledgements}

The following financial support is gratefully acknowledged from: the Swiss National Science Foundation (project $\mathrm{n}^{\circ} 205321-109709$ / 1 to EM), the University of Alaska Anchorage Faculty Development Grant to EM, a Queen Mary University of London Westfield studentship to RJP, a British School at Athens MacMillan-Rodewald fellowship to RJP, a University of Manchester Humanities Research Fellowship to RJP, the State Forests of Poland (project "Functions of natural and seminatural peatlands in nature and management structure of Tuchola Pinewoods", Principal Investigator: Kazimierz Tobolski), and the Polish Ministry of Scientific Research and Information Technology (project "Development and origin of mires situated in Stążka Valley in Tuchola Landscape Park"No. 3P04G04323, Principal Investigator: M. Lamentowicz.

\section{REFERENCES}

Barker P.A. 1992. Differential diatom dissolution in Late Quaternary sediments from Lake Manyara, Tanzania: an experimental approach. J Paleolimnol 7: 235-251. 
Birks H.J.B. and Birks H.H. 1980. Quaternary Paleoecology. Arnold. London.

Bonnet L. 1958. Les thécamoebiens des Bouillouses. Bull Soc Hist Nat Toulouse 93: $529-543$.

Booth R.K. 2002. Testate amoebae as paleoindicators of surface-moisture changes on Michigan peatlands: modern ecology and hydrological calibration. J Paleolimnol 28: 329-348.

Campbell I.D. 1999. Quaternary pollen taphonomy: examples of differential redeposition and differential preservation. Palaeogeogr Palaeocl 149: 245-256.

Chacharonis P. 1954. Observations on the ecology of protozoa associated with Sphagnum. Department of Zoology and Entomology. Ohio State University, p. 77.

Chacharonis P. 1956. Observations on the ecology of protozoa associated with Sphagnum. J Protozool 3: 11.

Coûteaux M.M. 1992. Decomposition of cells and empty shells of testate amebas (Rhizopoda, Testacea) in an organic-acid soil sterilized by propylene-oxide fumigation, autoclaving, and Gamma-ray irradiation. Biol Fertil Soils 12: 290294.

Kontrovitz M., Pani E.A. and Bray H. 1998. Experimental crushing of some podocopid ostracode valves: An aspect of taphonomy. Palaios 13: 500-507.

Lamentowicz M. 2005. Geneza torfowisk naturalnych i seminaturalnych w Nadleśnictwie Tuchola. Department of Biogeography and Palaeoecology. Adam Mickiewicz University, Poland.

Lamentowicz M. and Mitchell E.A.D. 2005. The ecology of testate amoebae (Protists) in Sphagnum in north-west Poland in relation to peatland ecology. Microb Ecol 50: $48-63$ 
Lamentowicz M., Mitchell E.A.D. and van der Knaap W.O. 2007. Reconstruction of climate during the last 1000 years from a high-resolution testate amoebae sequence in Switzerland. In: N. R. Catto (ed.), XVII INQUA Congress The Tropics: Heat Engine of the Quaternary. Quaternary International, Cairns, Australia, p. 429.

Lamentowicz M., Obremska M. and Mitchell E.A.D. In prep. The Holocene developmental history of Tuchola kettle-hole mire (northern Poland).

Lamentowicz M., Tobolski K. and Mitchell E.A.D. In Press. Palaeoecological evidence for anthropogenic acidification of a kettle-hole peatland in northern Poland. Holocene In press.

Lousier J.D. and Parkinson D. 1981. The Disappearance of the Empty Tests of LitterTestate and Soil-Testate Amebas (Testacea, Rhizopoda, Protozoa). Arch Protistenkd 124: 312-336.

Meisterfeld R. 1977. Die horizontale und vertikale Verteilung der Testaceen (Rhizopoda: Testacea) in Sphagnum. Arch Hydrobiol 79: 319-356.

Mitchell E.A.D., Buttler A.J., Warner B.G. and Gobat J.M. 1999. Ecology of testate amoebae (Protozoa : Rhizopoda) in Sphagnum peatlands in the Jura mountains, Switzerland and France. Ecoscience 6: 565-576.

Mitchell E.A.D. and Gilbert D. 2004. Vertical Micro-Distribution and Response to Nitrogen Deposition of Testate Amoebae in Sphagnum. J Eukaryot Microbiol 51: 485-495.

Mitchell E.A.D. and Meisterfeld R. 2005. Taxonomic confusion blurs the debate on cosmopolitanism versus local endemism of free-living protists Protist 156: 263267. 
Mitchell E.A.D., van der Knaap W.O., van Leeuwen J.F.N., Buttler A., Warner B.G. and Gobat J.M. 2001. The palaeoecological history of the Praz-Rodet bog (Swiss Jura) based on pollen, plant macrofossils and testate amoebae (Protozoa). Holocene 11: 65-80.

Opravilova V. and Hajek M. 2006. The variation of testacean assemblages (Rhizopoda) along the complete base-richness gradient in fens: A case study from the Western Carpathians. Acta Protozool 45: 191-204.

Payne R. and Mitchell E.A.D. 2007. Testate amoebae-environment relationships and a hydrological transfer function from mires in the Central Rhodope Mountains, Greece. Protist 158: 159-171.

Payne R.J., Kishaba K., Blackford J.J. and Mitchell E.A.D. 2006. Ecology of testate amoebae (Protista) in south-central Alaska peatlands: building transfer-function models for palaeoenvironmental studies. Holocene 16: 403-414.

Roe H.M., Charman D.J. and Gehrels W.R. 2002. Fossil testate amoebae in coastal deposits in the UK: implications for studies of sea-level change. J Quaternary Sci 17: 411-429.

Ruzicka E. 1982. Die subfossile Testaceen des Krottensees (Salzburg, Oesterreich). Limnol 1: 49-88.

Swindles G.T. and Roe H.M. 2007. Examining the dissolution characteristics of testate amoebae (Protozoa: Rhizopoda) in low pH conditions: Implications for peatland palaeoclimate studies. Palaeogeogr Palaeocl: doi:10.1016/j.palaeo.2007.1005.1004.

Tolonen K. 1986. Rhizopod analysis. In: B. E. Berglund (ed.), Handbook of Holocene Palaeoecology and Palaeohydrology. John Wiley and Sons, Chichester, pp. 645666. 
Wilmshurst J.M., Wiser S.K. and Charman D.J. 2003. Reconstructing Holocene water tables in New Zealand using testate amoebae: differential preservation of tests and implications for the use of transfer functions. Holocene 13: 61-72. 
TABLES

Table 1 Data filtering scenarios used to assess the effect of selective loss of certain testate amoeba shell types on inferred depth to water table

\begin{tabular}{|c|c|c|c|c|c|c|c|c|c|}
\hline \multicolumn{6}{|c|}{ Fraction of initial population remaining [\%] } & \multicolumn{4}{|c|}{ Fraction of initial population remaining [\%] } \\
\hline $\begin{array}{c}\text { Case } \\
\mathrm{nr}\end{array}$ & Idiosomes & $\begin{array}{c}\text { Idiosomes }+ \\
\text { organic }\end{array}$ & $\begin{array}{l}\text { Protein or } \\
\text { calcium }\end{array}$ & Xenosomes & $\begin{array}{c}\text { Case } \\
\mathrm{nr}\end{array}$ & Idiosomes & $\begin{array}{c}\text { Idiosomes }+ \\
\text { organic }\end{array}$ & $\begin{array}{l}\text { Protein or } \\
\text { calcium }\end{array}$ & Xenosomes \\
\hline 0 & 100 & 100 & 100 & 100 & 41 & 10 & 60 & 60 & 40 \\
\hline 1 & 0 & 40 & 40 & 10 & 42 & 10 & 60 & 60 & 60 \\
\hline 2 & 0 & 40 & 40 & 40 & 43 & 10 & 60 & 90 & 10 \\
\hline 5 & 0 & 40 & 60 & 40 & 46 & 10 & 90 & 40 & 10 \\
\hline 6 & 0 & 40 & 60 & 60 & 47 & 10 & 90 & 40 & 40 \\
\hline 7 & 0 & 40 & 90 & 10 & 48 & 10 & 90 & 40 & 60 \\
\hline 8 & 0 & 40 & 90 & 40 & 49 & 10 & 90 & 60 & 10 \\
\hline 9 & 0 & 40 & 90 & 60 & 50 & 10 & 90 & 60 & 40 \\
\hline 10 & 0 & 60 & 40 & 10 & 51 & 10 & 90 & 60 & 60 \\
\hline 15 & 0 & 60 & 60 & 60 & 56 & 40 & 40 & 40 & 40 \\
\hline 16 & 0 & 60 & 90 & 10 & 57 & 40 & 40 & 40 & 60 \\
\hline 17 & 0 & 60 & 90 & 40 & 58 & 40 & 40 & 60 & 10 \\
\hline 18 & 0 & 60 & 90 & 60 & 59 & 40 & 40 & 60 & 40 \\
\hline 19 & 0 & 90 & 40 & 10 & 60 & 40 & 40 & 60 & 60 \\
\hline 20 & 0 & 90 & 40 & 40 & 61 & 40 & 40 & 90 & 10 \\
\hline 21 & 0 & 90 & 40 & 60 & 62 & 40 & 40 & 90 & 40 \\
\hline 22 & 0 & 90 & 60 & 10 & 63 & 40 & 40 & 90 & 60 \\
\hline 23 & 0 & 90 & 60 & 40 & 64 & 40 & 60 & 40 & 10 \\
\hline 24 & 0 & 90 & 60 & 60 & 65 & 40 & 60 & 40 & 40 \\
\hline 25 & 0 & 90 & 90 & 10 & 66 & 40 & 60 & 40 & 60 \\
\hline 26 & 0 & 90 & 90 & 40 & 67 & 40 & 60 & 60 & 10 \\
\hline 32 & 10 & 40 & 60 & 40 & 73 & 40 & 90 & 40 & 10 \\
\hline 33 & 10 & 40 & 60 & 60 & 74 & 40 & 90 & 40 & 40 \\
\hline 34 & 10 & 40 & 90 & 10 & 75 & 40 & 90 & 40 & 60 \\
\hline 35 & 10 & 40 & 90 & 40 & 76 & 40 & 90 & 60 & 10 \\
\hline 36 & 10 & 40 & 90 & 60 & 77 & 40 & 90 & 60 & 40 \\
\hline 37 & 10 & 60 & 40 & 10 & 78 & 40 & 90 & 60 & 60 \\
\hline 38 & 10 & 60 & 40 & 40 & 79 & 40 & 90 & 90 & 10 \\
\hline 39 & 10 & 60 & 40 & 60 & 80 & 40 & 90 & 90 & 40 \\
\hline 40 & 10 & 60 & 60 & 10 & 81 & 40 & 90 & 90 & 60 \\
\hline
\end{tabular}




\section{FIGURES}

Figure 1. Relative abundance profiles of four types of testate amoeba shell types in three peat profiles.

Figure 2 Biplots of testate amoeba relative abundance in relation to depth to the water table (DWT) for each of four categories of shell types and effect of selective removal of that type on the DWT prediction. Data from Sphagnum-dominated peatlands of the Jura Mountains Switzerland and France (Mitchell et al. 1999; Mitchell et al. 2001).

Figure 3 Biplots of testate amoeba relative abundance in relation to depth to the water table (DWT) for each of four categories of shell types and effect of selective removal of that type on the DWT prediction. Data from Sphagnum-dominated peatlands of South-Central Alaska (Payne et al. 2006).

Figure 4. Biplots of testate amoeba relative abundance in relation to depth to the water table (DWT) for each of four categories of shell types and effect of selective removal of that type on the DWT prediction. Data from minerotrophic peatlands of Northern Greece (Payne and Mitchell 2007).

Figure 5. Average bias from measured depth to water table (DWT) for transfer functions with each of four categories of shell types selectively removed for the three training sets from the Jura Mountains, Alaska and Greece. For each category the first bar corresponds to the full model and subsequent bars represent models with increasing removals of that type (in 10\% steps). 
Figure 6. Summarised performance of the transfer function models with the full data set and 81 simulated cases of differential loss of the four categories of shell type. Shades of grey indicate the percentage of remaining shells for each shell-type. The horizontal line corresponds to the performance of the full data set (far left).

Figure 7. Biplots of observed vs. predicted depth to water table (DWT) based on testate amoebae in three data sets and effect of differential dissolution of shells (referred to as "limited model") as observed by Swindles \& Roe (2007). 

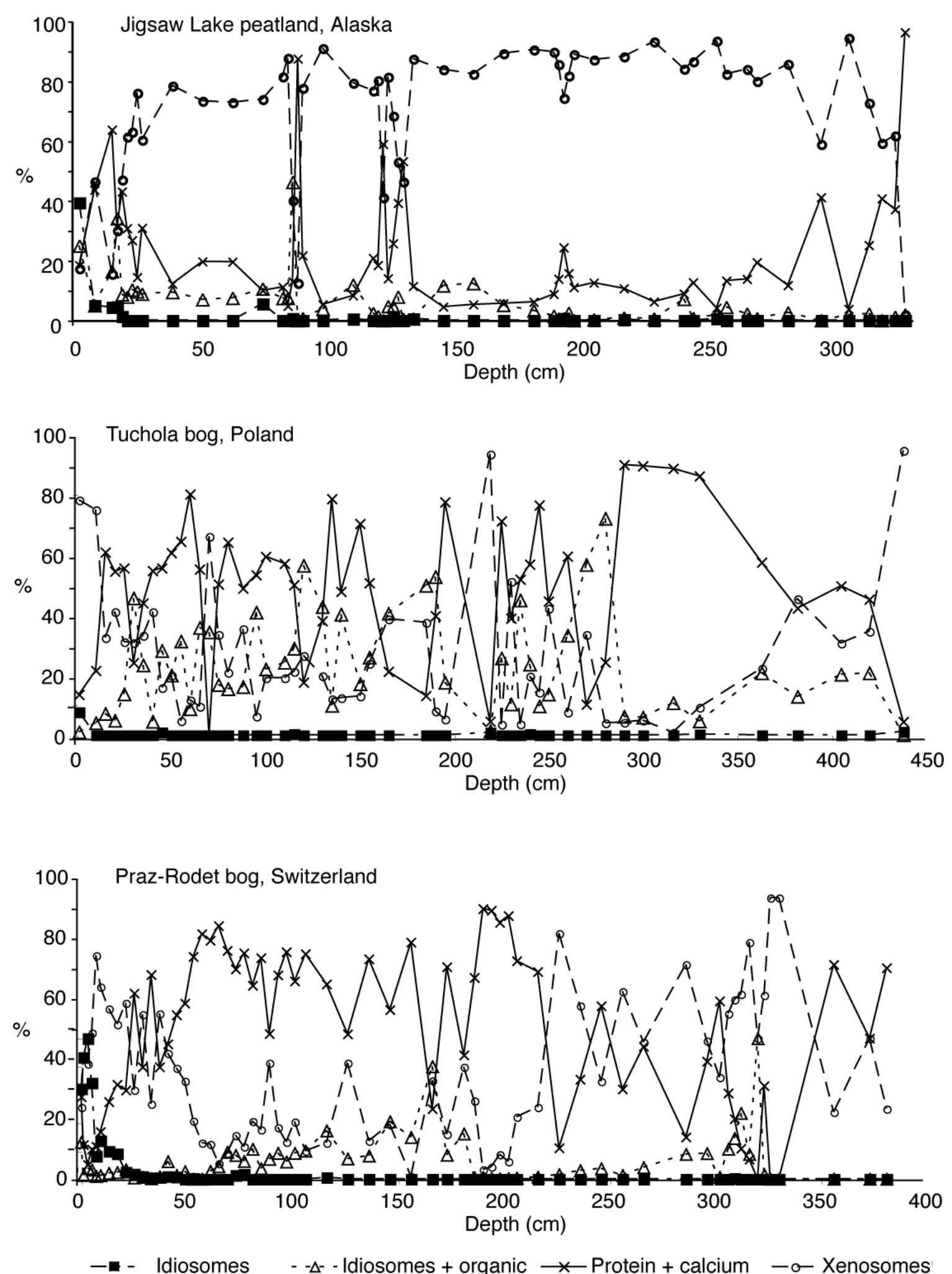

Figure 1 

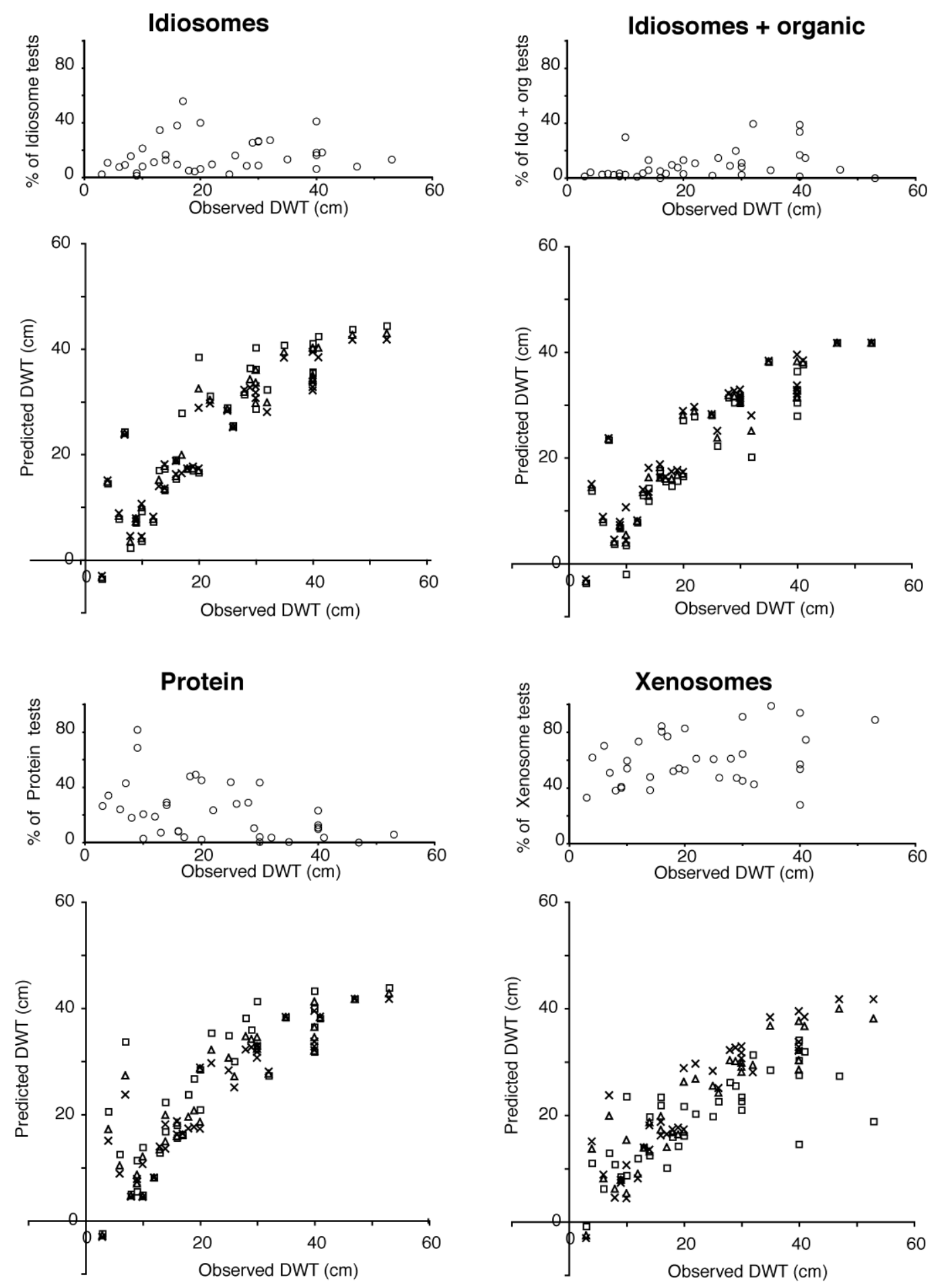

\begin{tabular}{|lll|}
\hline$\times$ Full model predicted & $\Delta 50 \%$ remaining & $\square 0 \%$ remaining \\
\hline
\end{tabular}

Figure 2 

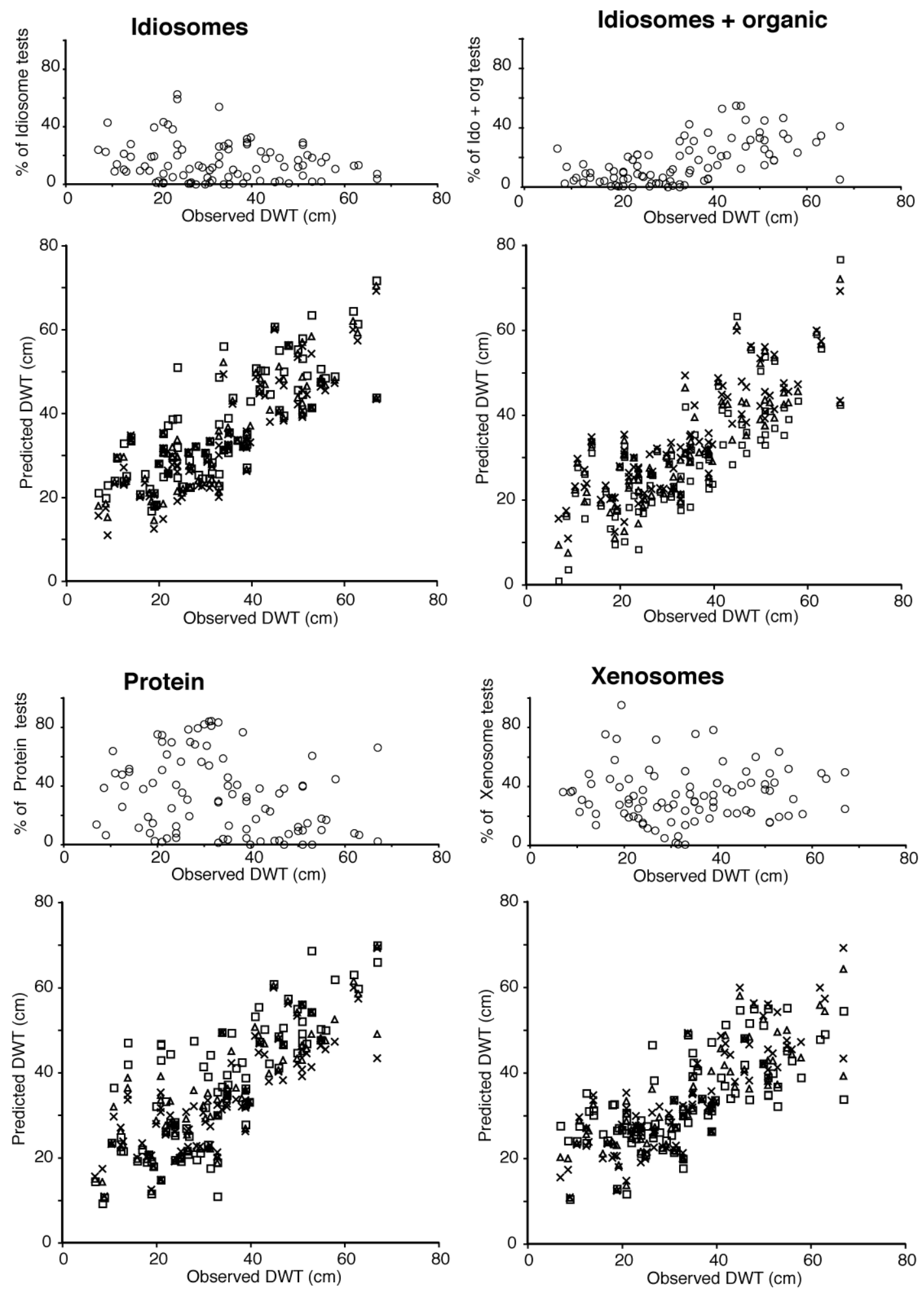

$$
\times \text { Full model predicted } \quad \Delta 50 \% \text { remaining } \quad \square 0 \% \text { remaining }
$$

Figure 3. 

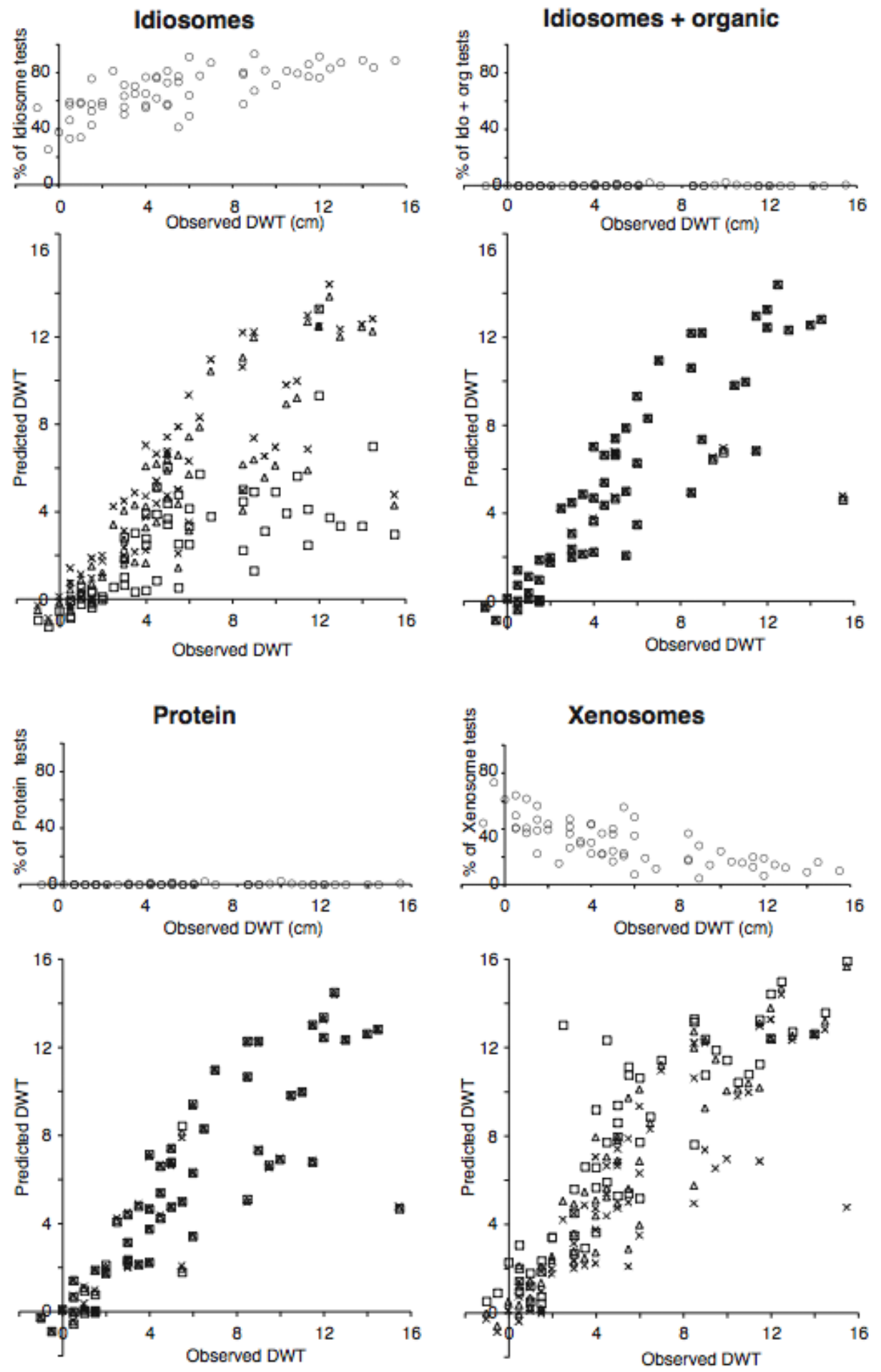

$\times$ Full model predicted $\quad \Delta 50 \%$ remaining $\quad$ a $0 \%$ remaining

Figure 4. 

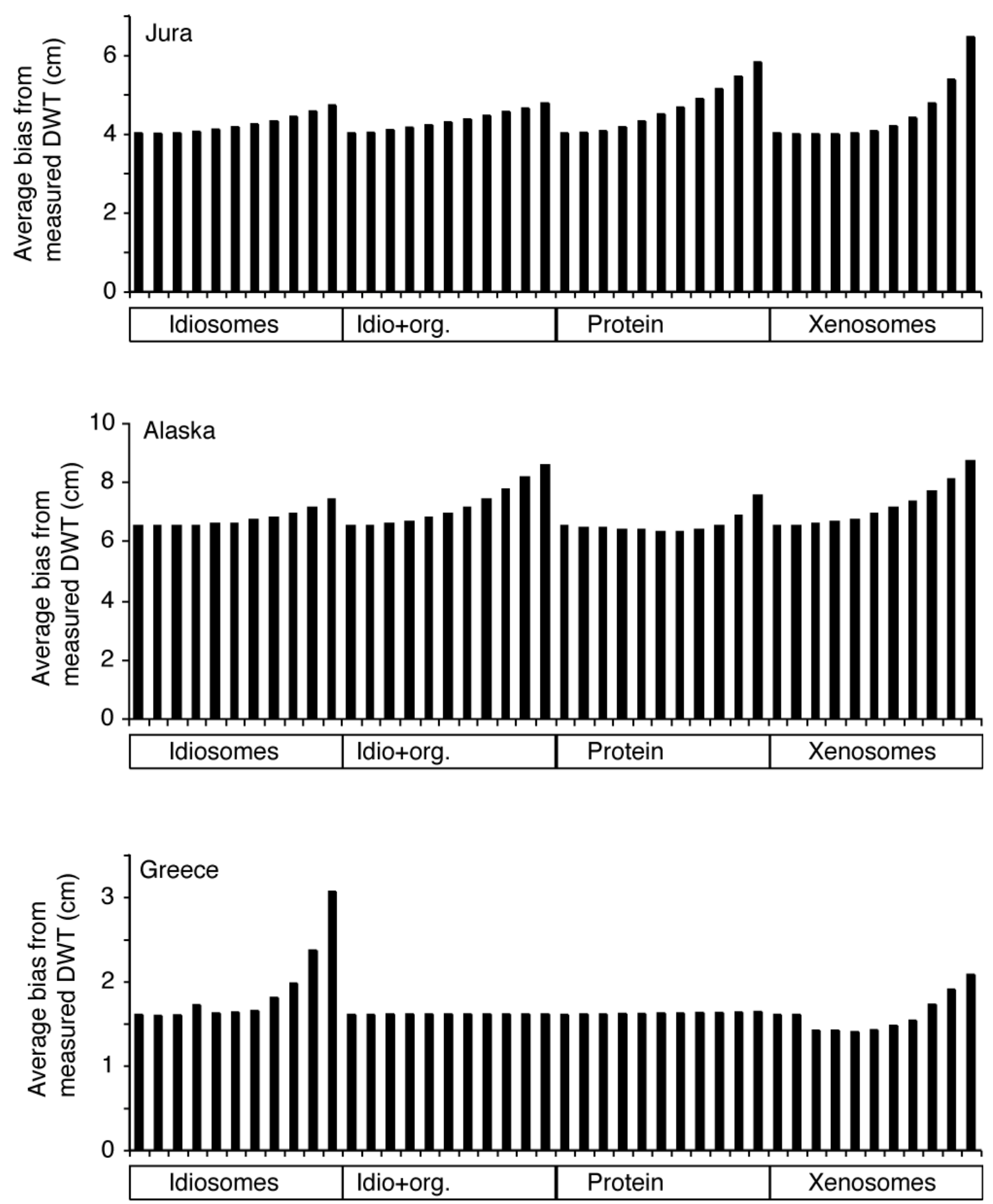

Figure 5. 

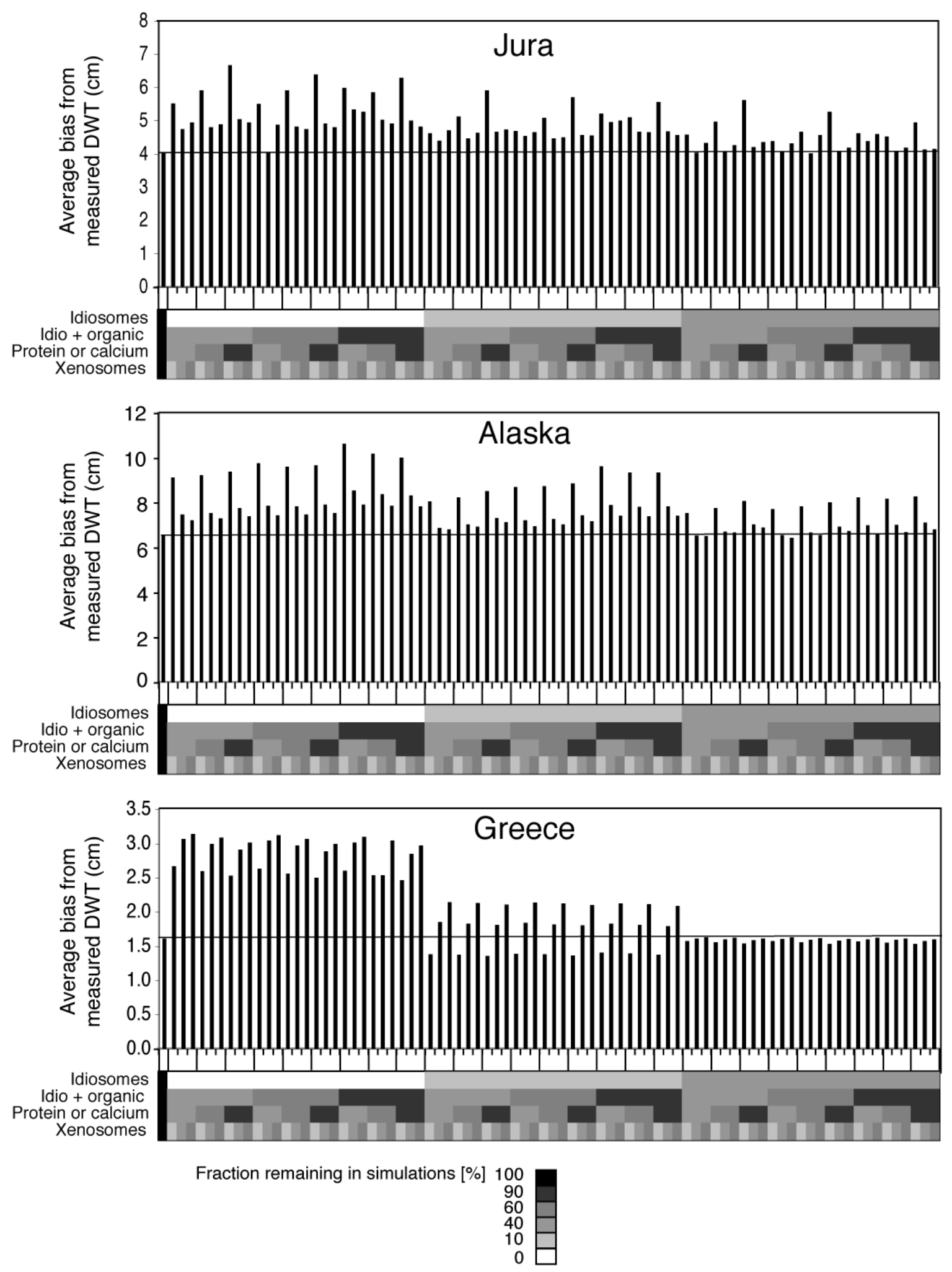

Figure 6. 

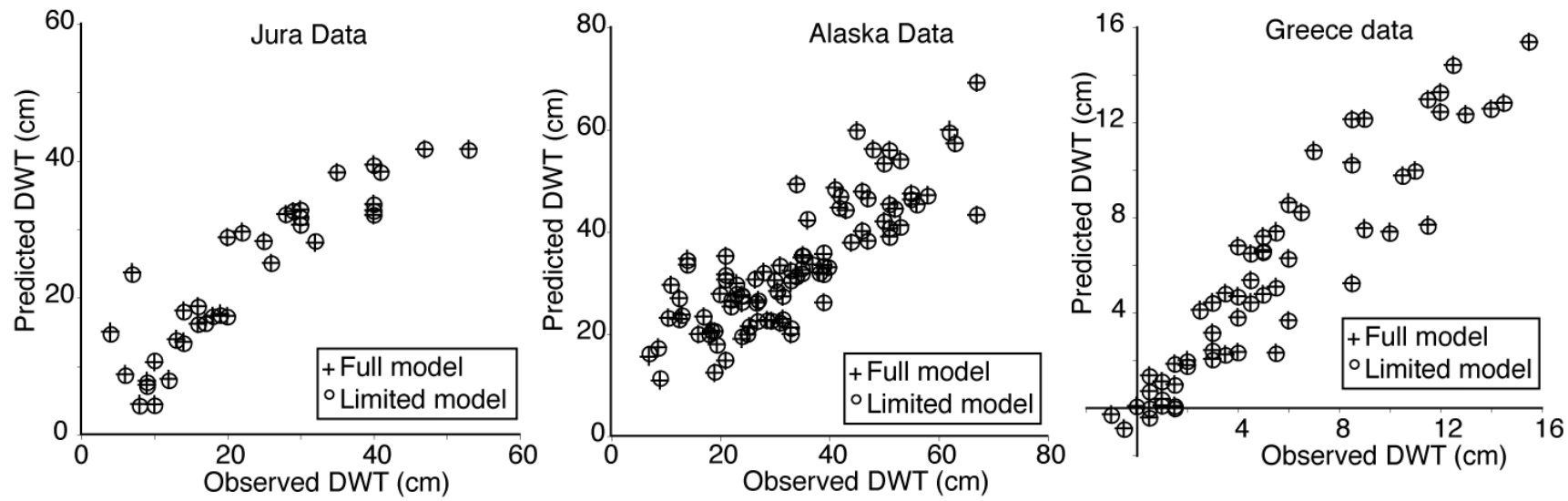

Figure 7 